\title{
Adherence to the World Cancer Research Fund/American Institute for Cancer Research recommendations for cancer prevention is associated with better health-related quality of life among long-term colorectal cancer survivors: results of the PROFILES registry
}

\author{
Merel R. van Veen ${ }^{1,2}$ (1) $\cdot$ Floortje Mols $^{3} \cdot$ Martijn J. L. Bours $^{4} \cdot$ Matty P. Weijenberg $^{4} \cdot$ Ellen Kampman $^{2} \cdot$ Sandra Beijer $^{1}$
}

Received: 24 September 2018 / Accepted: 5 March 2019/Published online: 29 March 2019

(C) The Author(s) 2019

\begin{abstract}
Since colorectal cancer (CRC) survivors often suffer from long-term adverse health effects of the cancer and its treatment, having a negative impact on their health-related quality of life (HRQL), this study focuses on the association between adherence to WCRF/AICR recommendations and HRQL among CRC survivors. In a cross-sectional PROFILES registry study in 1096 CRC survivors (mean time since diagnosis 8.1 years), WCRF/AICR adherence scores (range $0-8$, with a higher score for better adherence) were calculated, and HRQL was assessed using the EORTC QLQ-C30. Associations between adherence scores and HRQL scores were investigated using linear regression analyses. Additionally, associations with adherence to guidelines for body mass index (BMI) (normal weight, overweight and obese), physical activity (PA) (score 0/1) and diet (score $<3,3-<4$ and $>4$ ) were evaluated separately. Mean adherence score was $4.81 \pm 1.04$. Higher WCRF/AICR scores were associated with better global health status $(\beta 1.64 ; 95 \% \mathrm{CI} 0.69 / 2.59)$, physical functioning $(\beta 2.71 ; 95 \% \mathrm{CI} 1.73 / 3.68)$, role functioning $(\beta 2.87$; $95 \%$ CI 1.53/4.21), cognitive functioning $(\beta 1.25 ; 95 \% \mathrm{CI} 0.19 / 2.32)$, social functioning $(\beta 2.01 ; 95 \% \mathrm{CI} 0.85 / 3.16)$ and fatigue $(\beta$ $-2.81 ; 95 \% \mathrm{CI}-4.02 /-1.60$ ). Adherence versus non-adherence PA was significantly associated with better physical, role, emotional and social functioning, global health status and less fatigue. Except for the association between being obese and physical functioning $(\beta-4.15 ; 95 \% \mathrm{CI}-47.16 /-1.15)$, no statistically significant associations with physical functioning were observed comparing adherence to non-adherence to BMI and dietary recommendations. Better adherence to the WCRF/AICR recommendations was positively associated with global health status, most functioning scales and less fatigue among CRC survivors. PA seemed to be the main contributor.
\end{abstract}

Keywords Colorectal cancer survivors $\cdot$ Health-related quality of life $\cdot$ WCRF guidelines $\cdot$ Dietary guidelines $\cdot$ Physical activity Body composition

Merel R. van Veen

merelrvanveen@gmail.com

1 Department of Research \& Development, Netherlands Comprehensive Cancer Organisation (IKNL), IKNL, P.O. Box 19079, 3501 DB Utrecht, The Netherlands

2 Division of Human Nutrition and Health, Wageningen University, P.O. Box 17, 6700 AA Wageningen, The Netherlands

3 CoRPS-Center of Research on Psychology in Somatic diseases, Department of Medical and Clinical Psychology, Tilburg University, PO Box 90153, 5000 LE Tilburg, The Netherlands

4 Department of Epidemiology, GROW - School for Oncology and Developmental Biology, Maastricht University, P.O. Box 616, 6200 MD Maastricht, The Netherlands

\section{Introduction}

In 2007, the World Cancer Research Fund/American Institute for Cancer Research (WCRF/AICR) launched the diet and physical activity recommendations for cancer prevention [1]. Cancer survivors, defined as people who are living with a diagnosis of cancer, including those who have recovered from the disease [1], or in other words those who finished treatment and are disease-free, are encouraged to follow these recommendations to reduce risk of recurrence and improve survival.

Colorectal cancer (CRC) survivors often suffer from longterm adverse health effects of cancer and its treatment [2]. This can have a negative impact on health-related quality of life (HRQL). Two systematic reviews showed that CRC survivors 
had a lower physical functioning and more fatigue and psychological problems, including depression, anxiety and distress than the general population [3, 4]. Because of the increasing numbers of CRC survivors, investigating possibilities to increase HRQL is very important.

Several studies showed an association between adherence to general non-cancer-specific dietary guidelines, such as the Healthy Eating Index or the Mediterranean diet, and higher levels of HRQL in cancer survivors, including CRC survivors [5-7]. In addition, previous studies have demonstrated that CRC survivors who met the public health exercise guidelines reported better quality of life (QL) and fatigue scores than CRC survivors who did not meet these guidelines $[8,9]$. Although adherence to general dietary or exercise guidelines showed positive associations with HRQL, the association between adherence to the cancer-specific WCRF/AICR recommendations on diet, physical activity and body weight/ composition and HRQL have only been investigated in female cancer survivors in general [10], in breast cancer survivors [11] and in a small cross-sectional study $(N=145)$ in CRC survivors [12]. These studies showed that better adherence to the WCRF/AICR recommendations was associated with better HRQL [10-12]. However, due to the relatively small numbers in these studies, it was not possible to evaluate which specific recommendations had the highest impact among CRC survivors (diet, physical activity or body composition). The aim of the present study was to investigate the association between adherence to the WCRF/AICR recommendations and HRQL for all recommendations together and for physical activity, body composition and diet separately in a large cohort of CRC survivors.

\section{Subjects and methods}

\section{Study design}

This study was part of an ongoing longitudinal study investigating HRQL in CRC patients. All CRC patients stage I-IV, diagnosed between January 2000 and June 2009 from the southern area of the Netherlands, were sampled via the Netherlands Cancer Registry (NCR). The Patient Reported Outcomes Following Initial Treatment and Long-term Evaluation of Survivorship (PROFILES) registry was used to collect the data [13].

Ethical approval for the study was obtained from the local certified Medical Ethics Committee of the Maxima Medical Centre Veldhoven, the Netherlands (approval number 0822). All participants gave informed consent. Data from this longitudinal study are (partly) available online for non-commercial scientific research, subject to study question, privacy and confidentiality restrictions, and registration (www.profilesregistry.nl).

\section{Data collection}

CRC patients were invited for participation via a letter from their (former) attending physician. The letter included a link to a secure website, a login name and a password, so that interested patients could provide consent and complete questionnaires online. Those who preferred written communication could return a postcard after which they received our paperand-pencil informed consent form and questionnaire. Nonrespondents were sent a reminder letter and paper-and-pencil questionnaire within 2 months. Patients were reassured that nonparticipation had no consequences for their follow-up care or treatment. The NCR provided information on cancer diagnosis and cancer treatment history, such as year of diagnosis, stage and localization of cancer and having a stoma.

\section{Study population}

The CRC study started in December 2010 and respondents received subsequent HRQL questionnaires in December 2011, December 2012 and January 2014. In August 2013, data on the adherence to WCRF/AICR recommendations were collected once. A complete overview of the selection of patients can be found on our website under 'data \& documentation'; https://www.dataarchive. profilesregistry.nl/study_units/view/22. In the current paper, we present data on the adherence to WCRF/AICR recommendations and data regarding HRQL of the subsequent measurement in January 2014. Patients with unverifiable addresses, with cognitive impairment, who died prior to the start of the study or were terminally ill, with stage 0/carcinoma in situ and those already included in our 2009 CRC study or another study $(n=169)$, were excluded [14]. One thousand six hundred twenty-five participants were invited for the data collection in August 2013, see Fig. 1. Between August 2013 and January 2014, 78 (4.8\%) participants died or discontinued participation, resulting in 1547 survivors who were invited for the questionnaire on HRQL in January 2014. Figure 1 gives an overview of the number of non-responders and excluded patients. Of the 1625 CRC survivors who were invited in August 2013, 1096 were included in the present study (67.4\% of invited participants in August 2013) (Fig. 1).

\section{Health-related quality of life}

The validated European Organization for Research and Treatment of Cancer-Quality of Life Questionnaire (EORTC QLQ)-C30 was used to assess HRQL and fatigue $[15,16]$. For CRC patients, previous research concludes that a healthy lifestyle is mainly associated with functioning scales (i.e. physical, emotional, social, cognitive and role functioning) and 


\section{Questionnaire on dietary intake \\ \& supplement use \\ (WCRF/DHD-FFQ) \\ August 2013}

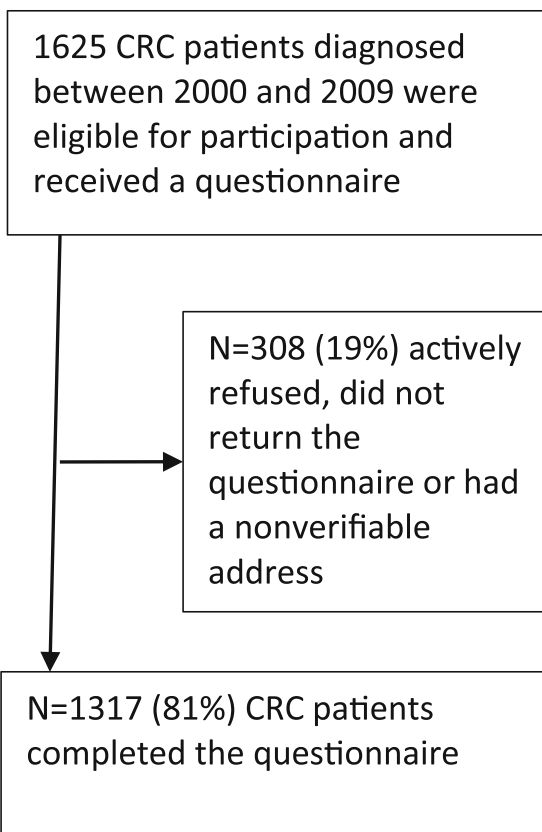

Questionnaire on HRQL and fatigue

January 2014

1547 CRC patients diagnosed between 2000 and 2009 were eligible for participation and received a questionnaire participants died or discontinued participation

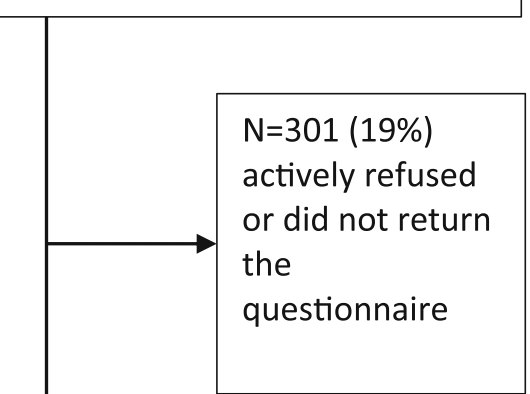

$\mathrm{N}=1246$ (81\%) CRC patients completed the questionnaire
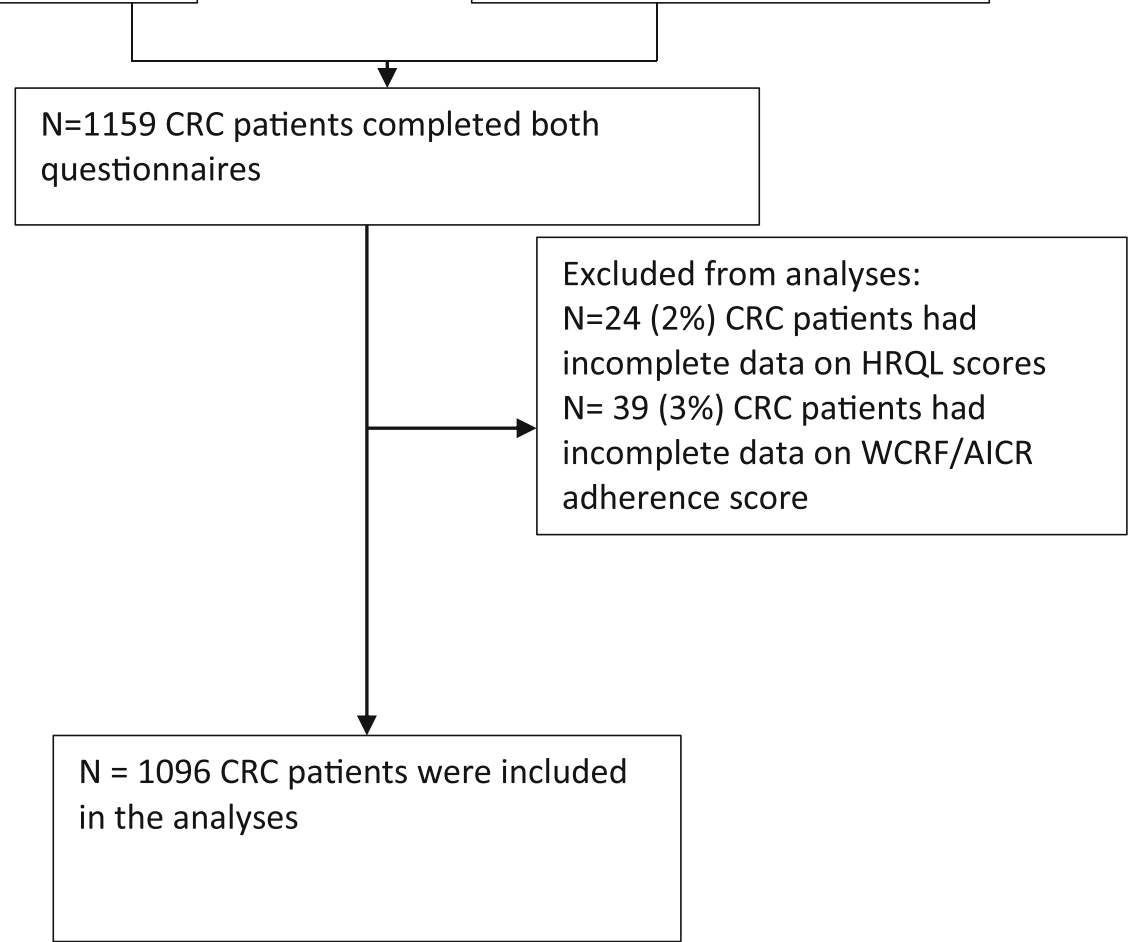

Fig. 1 Flowchart of the study population

fatigue $[5,17]$. Therefore, only functioning scales, fatigue and global health status were included in the analysis. All items were scored on a 4-point Likert scale ranging from 'not at all' to 'very much', except for the items regarding global health 
status which were scored from 1 (very poor) to 7 (excellent). All scores were linearly transformed to a scale ranging from 0 to 100 points $[15,18]$. Higher scores on functioning scales represent better functioning, while a higher score on the fatigue scale corresponds to more fatigue.

Changes in scores were considered clinically relevant if the mean difference was 5-14 points for physical functioning, 511 points for social functioning, 3-9 points for cognitive functioning, 6-19 points for role functioning and 5-13 point for fatigue [19]. For emotional functioning no cut-offs were defined [19].

\section{Adherence to the WCRF/AICR recommendations}

Adherence to the eight WCRF/AICR recommendations was determined, six recommendations about healthy diet, one about body fatness and one about physical activity. The scoring of adherence to the WCRF/AICR recommendations is described extensively by Winkels et al. [20] and Romaguera et al. [21].

With regard to a healthy diet, in 2007 , the WCRF/AICR published the following recommendations: 'foods and drinks that promote weight gain: avoid high-calorie foods and sugary drinks', 'plant-based foods: eat more grains, vegetables, fruit and beans', 'animal foods: limit red meat and avoid processed meat', 'alcoholic drinks: for cancer prevention, don't drink alcohol', 'preservation, processing \& preparation: eat less salt and avoid mouldy grains \& cereals' and 'dietary supplement use: for cancer prevention, don't rely on supplements'. To assess adherence to the recommendations concerning healthy diet, the Dutch Healthy Diet-Food Frequency Questionnaire (DHD-FFQ) was used [22]. The original DHD-FFQ consists of 34 items. To compensate for items that were missing in the DHD-FFQ but are incorporated in the WCRF/AICR recommendations, additional questions on intake of meat, processed meat and sugary beverages were added to the questionnaire, from now on called WCRF/DHD-FFQ. The WCRF/DHD-FFQ consists of 40 items on intakes of bread, fruit, vegetable, potatoes, milk, cheese, meat products, fish, cookies, pastries, crisps, soup, fats and oils, takeaway food, pizza, sugary drinks, alcoholic beverages and discretionary salt.

Adherence to the recommendation regarding body fatness was determined based on body mass index (BMI) by calculating weight $(\mathrm{kg}) /$ height $(\mathrm{m})^{2}$. Weight and height were selfreported. BMI was categorised as normal weight $(18.5<\mathrm{BMI}$ $\left.<25 \mathrm{~kg} / \mathrm{m}^{2}\right)$, overweight $\left(25>\mathrm{BMI}<30 \mathrm{~kg} / \mathrm{m}^{2}\right)$ or obesity $\left(\mathrm{BMI}>30 \mathrm{~kg} / \mathrm{m}^{2}\right)$.

Physical activity was assessed using the Short Questionnaire to Assess Health-Enhancing Physical Activity (SQUASH) which contains questions about multiple activities referring to a normal week in the past month. Results were converted to time spent in light, moderate and vigorous activities, which were then converted to activity scores [23]. When this total activity score was 5 or more, representing the number of activities of at least $30 \mathrm{~min}$ per week, persons were categorised as adherent to the physical activity recommendation. If one of the recommendations was met, participants received 1 point for that recommendation.

When a recommendation was not met, 0 or 0.5 points were allotted according to the available cut-off values. The total score had a range of $0-8$; a higher score means better adherence to the recommendations [20].

\section{Analysis and statistical methods}

Responders were compared to non-responders. The CRC survivors were categorised into three groups, based on tertiles of WCRF/AICR adherence scores following the sample distribution. Chi-square (categorical variables) and one-way ANOVA (continuous variables) were used to test for differences in baseline characteristics.

To assess the association between WCRF adherence scores and HRQL, linear regression models were used both for the tertiles and for the continuous adherence scores. The following variables were tested whether they changed the regression coefficient by at least $10 \%$ [24]: gender, age, comorbidities, smoking status, years since diagnosis, tumour localization, tumour stage, having a stoma, chemotherapy and radiotherapy; and for the analyses of the individual components diet, physical activity and BMI. Gender (male/female), age (continuous), comorbidities (no comorbidities, 1 comorbidity, $\geq 2$ comorbidities) and smoking (current, former, never) changed the regression coefficient $\geq 10 \%$ and were included in the multivariable model. For the analyses of the individual components, diet and BMI changed by $>10 \%$ when physical activity was added to the model, therefore physical activity was added to the multivariable model. Dummy variables were created for WCRF/AICR adherence score tertiles, smoking status and comorbidities.

Functioning scales, global health status and fatigue were also examined separately in relation to each of the three components of the adherence score (BMI (normal weight, overweight and obese), physical activity (score 0/1) and diet (low adherence (score $<3$ points), moderate adherence (score $3-<$ 4 points) and high adherence ( $>4$ points)). To evaluate the effect of the separate components of adherence scores on the functioning scales, global health status and fatigue beyond the effects of the other components, the analysis of each component was adjusted for the other components.

A $p$ value $<0.05$ was regarded as statistically significant. All analyses were conducted using the Statistical Package for Social Sciences (SPSS) version 23.0 (IBM). 


\section{Results}

\section{General characteristics of the study population}

Respondents of our study were most often male, $>65$ years old, had two or more comorbidities, were former smokers, had a mean time since diagnosis of 8.1 years, had a colon tumour, stage II, and did not receive chemotherapy or radiotherapy (Table 1). When comparing the non-respondents and excluded respondents to the included respondents, non-respondents and excluded respondents did not differ from respondents (data not shown).

The mean total WCRF/AICR adherence score was $4.81 \pm$ 1.04 of a total of 8 points (range 1.33-8.00).

Higher WCRF/AICR adherence scores were more common among women compared to men. The highest WCRF/ AICR adherence scores were found among survivors who never smoked, among older participants and among

Table 1 Sociodemographic and clinical characteristics for the three tertiles of WCRF/AICR adherence scores $(N=1096)$

\begin{tabular}{|c|c|c|c|c|c|}
\hline & & $\begin{array}{l}\text { Total population } \\
N(\%)\end{array}$ & $\begin{array}{l}\text { Tertile } 1 \mathrm{WCRF} \\
\text { adherence score } \\
<4.42 \text { points } \\
N(\%)\end{array}$ & $\begin{array}{l}\text { Tertile } 2 \text { WCRF } \\
\text { adherence score } \\
4.42-5.33 \text { points } \\
N(\%)\end{array}$ & $\begin{array}{l}\text { Tertile } 3 \text { WCRF } \\
\text { adherence score } \\
>5.33 \text { points } \\
N(\%)\end{array}$ \\
\hline \multirow{4}{*}{$\begin{array}{l}N \\
\text { Gender }\end{array}$} & $1096(100 \%)$ & $360(33 \%)$ & $365(33 \%)$ & $371(34 \%)$ & \\
\hline & Male & $635(58 \%)$ & $227(63 \%)$ & $209(63 \%)$ & $179(48 \%)$ \\
\hline & Female & $461(42 \%)$ & $133(37 \%)$ & $136(37 \%)$ & $192(52 \%)$ \\
\hline & Missing & 0 & 0 & 0 & 0 \\
\hline \multirow[t]{4}{*}{ Age* } & Mean age $($ years $+\mathrm{SD})$ & $70.8+9.2$ & $69.7+9.5$ & $70.9+9.1$ & $71.7+8.9$ \\
\hline & $<65$ years & $264(\overline{2} 4 \%)$ & $102(\overline{2} 8 \%)$ & $89(2 \overline{4} \%)$ & $73(2 \overline{0} \%)$ \\
\hline & $>65$ years & $832(76 \%)$ & $258(72 \%)$ & $276(76 \%)$ & $298(80 \%)$ \\
\hline & Missing & 0 & 0 & 0 & 0 \\
\hline \multicolumn{6}{|c|}{ Comorbidities } \\
\hline & 0 & $261(24 \%)$ & $76(21 \%)$ & $85(23 \%)$ & $100(27 \%)$ \\
\hline & 1 & $306(28 \%)$ & $96(27 \%)$ & $102(28 \%)$ & $108(29 \%)$ \\
\hline & $>2$ & $495(45 \%)$ & $183(51 \%)$ & $163(45 \%)$ & $149(40 \%)$ \\
\hline & $\bar{M}$ issing & $34(3 \%)$ & $5(1 \%)$ & $15(4 \%)$ & $14(4 \%)$ \\
\hline \multicolumn{6}{|c|}{ Smoking* } \\
\hline & Current & $85(8 \%)$ & $33(9 \%)$ & $26(7 \%)$ & $26(7 \%)$ \\
\hline & Former & $667(61 \%)$ & $237(66 \%)$ & $224(61 \%)$ & $206(56 \%)$ \\
\hline & Never & $322(29 \%)$ & $83(23 \%)$ & $106(29 \%)$ & $133(36 \%)$ \\
\hline & Missing & $22(2 \%)$ & $7(2 \%)$ & $9(3 \%)$ & $6(2 \%)$ \\
\hline \multicolumn{6}{|c|}{ Years since diagnosis } \\
\hline & Mean time since diagnosis (SD) & $8.1+2.8$ & $8.1+2.8$ & $8.2+2.8$ & $7.9+2.8$ \\
\hline & $<5$ years & $116 \overline{(} 11 \%)$ & $39(\overline{1} 1 \%)$ & $32(\overline{9} \%)$ & $45(\overline{1} 2 \%)$ \\
\hline & $>5$ years & $980(89 \%)$ & $321(89 \%)$ & $333(30 \%)$ & $326(88 \%)$ \\
\hline & Missing & 0 & 0 & 0 & 0 \\
\hline \multicolumn{6}{|c|}{ Tumour localization } \\
\hline & Colon & $634(58 \%)$ & $204(57 \%)$ & $211(58 \%)$ & $219(59 \%)$ \\
\hline & Rectum & $462(42 \%)$ & $156(43 \%)$ & $154(42 \%)$ & $152(41 \%)$ \\
\hline & Missing & 0 & 0 & 0 & 0 \\
\hline \multicolumn{6}{|c|}{ Tumour stage } \\
\hline & Stage I & $348(32 \%)$ & $111(31 \%)$ & $112(31 \%)$ & $125(34 \%)$ \\
\hline & Stage II & $372(34 \%)$ & $108(30 \%)$ & $129(35 \%)$ & $135(37 \%)$ \\
\hline & Stage III & $318(29 \%)$ & $119(33 \%)$ & $101(28 \%)$ & $98(26 \%)$ \\
\hline & Stage IV & $26(2 \%)$ & $10(3 \%)$ & $12(3 \%)$ & $4(1 \%)$ \\
\hline & Missing & $31(3 \%)$ & $12(3 \%)$ & $11(3 \%)$ & $8(2 \%)$ \\
\hline \multicolumn{6}{|l|}{ Stoma } \\
\hline & Yes & $168(15 \%)$ & $58(16 \%)$ & $46(13 \%)$ & $64(17 \%)$ \\
\hline & No & $928(85 \%)$ & $302(84 \%)$ & $319(87 \%)$ & $307(83 \%)$ \\
\hline & Missing & 0 & 0 & 0 & 0 \\
\hline \multicolumn{6}{|c|}{ Chemotherapy* } \\
\hline & Yes & $329(30 \%)$ & $128(36 \%)$ & $113(31 \%)$ & $88(24 \%)$ \\
\hline & No & $767(70 \%)$ & $232(64 \%)$ & $252(69 \%)$ & $283(76 \%)$ \\
\hline & Missing & 0 & 0 & 0 & 0 \\
\hline \multicolumn{6}{|c|}{ Radiotherapy } \\
\hline & Yes & $370(34 \%)$ & $125(35 \%)$ & $119(33 \%)$ & $126(34 \%)$ \\
\hline & No & $726(66 \%)$ & $235(65 \%)$ & $246(67 \%)$ & $245(66 \%)$ \\
\hline & Missing & 0 & 0 & 0 & 0 \\
\hline
\end{tabular}

$* p<0.05$ 
participants who did not receive chemotherapy (Table 1). Years since diagnosis, tumour localization and stage, having a stoma, comorbidities and receiving radiotherapy, were evenly distributed among the tertiles of WCRF/AICR adherence scores. Thirty-four percent of respondents adhered to the BMI recommendation: 'maintain body weight within the normal range from age 21; BMI $18.5<25 \mathrm{~kg} / \mathrm{m}^{2}, 75 \%$ adhered to the physical activity recommendation: 'be moderately physically active, equivalent to brisk walking, for at least $30 \mathrm{~min}$ every day' and the mean dietary adherence score was $3.48+$ 0.87 of a total of 6 points (range $0.5-6.0$ ). Fifty-eight percent adhered to the recommendation 'foods and drinks that promote weight gain: avoid sugary drinks' with adherence $=$ no sugary drinks, $10 \%$ adhered to 'plant-based foods: at least five portions/servings (at least $400 \mathrm{~g}$ ) of a variety of non- starchy vegetables of fruits every day' with adherence $=$ a mean fruit and vegetable intake $>400 \mathrm{~g} /$ day and dietary fibre $>17 \mathrm{~g} /$ day, $8 \%$ to 'meat products: people who eat red meat to consume less than $500 \mathrm{~g} /$ week, very little, if any, to be processed' with adherence $=\mathrm{red} /$ processed meat $<500 \mathrm{~g} /$ week of which processed meat $<3 \mathrm{~g} /$ day, $73 \%$ to 'alcoholic drinks: If alcoholic drinks are consumed, limit consumption to no more than two drinks a day for men, and one drink a day for women', $12 \%$ to 'preservation, processing \& preparation: Limit consumption of processed foods with added salt to ensure an intake of $<6 \mathrm{~g}$ ( $2.4 \mathrm{~g}$ sodium) a day' and $75 \%$ to the recommendation on 'dietary supplement use: Dietary supplements are not recommended for cancer prevention'.

Higher HRQL scores were seen among men (physical, role, emotional functioning and global health status), for younger participants ( $<65$ years old) (physical and emotional functioning), CRC survivors without comorbid conditions (for physical, role, emotional, cognitive, social functioning and global health status and fatigue) and those who never smoked (emotional functioning and global health status). For years since diagnosis, tumour localization, tumour stage, having a stoma, receiving chemotherapy and radiotherapy, no significant differences in HRQL was found (data not shown).

\section{Health-Related Quality of Life}

Survivors with the highest WCRF/AICR adherence scores (tertile $3 ;>5.25$ points) had the highest mean physical functioning scores $(84.8 \pm 17.2$ vs. $78.3 \pm 21.3)$ and role functioning scores $(86.5 \pm 2 \overline{1} .7$ vs. $78.3 \pm 2 \overline{7} .7)$ and the lowest mean scores on fatigue $(16.6 \pm 19.7$ vs. $24.7 \pm 23.7)$, compared to survivors with the lowest WCRF/AICR adherence scores (tertile $1 ;<4.42$ points; see Fig. 2). Although small, these differences are considered clinically relevant [19].

Multivariable linear regression models (Table 2) showed that compared to the lowest tertile $(<4.42$ points), the second (4.42-5.25 points) and the third tertile ( $>5.25$ points) of the WCRF/AICR adherence score were significantly associated with higher scores on physical, role and social functioning and a lower level of fatigue. The highest tertile of the adherence score was significantly associated with higher scores on emotional functioning, cognitive functioning and global health status compared to the lowest tertile. For an increase in the continuous score of adherence to the WCRF/AICR recommendations, significant associations were found for better physical functioning, role functioning, cognitive functioning, social functioning and global health status and less fatigue.

Multivariable linear regression models showed that adherence to the physical activity recommendation was associated with better physical, role, emotional and social functioning, better global health status and less fatigue (Table 3). Being overweight was not significantly associated with different
Fig. 2 HRQL scores by WCRF/AICR adherence scores $(N=1096)$. A single asterisk denotes small clinically relevant difference between tertile 1 and tertile 3

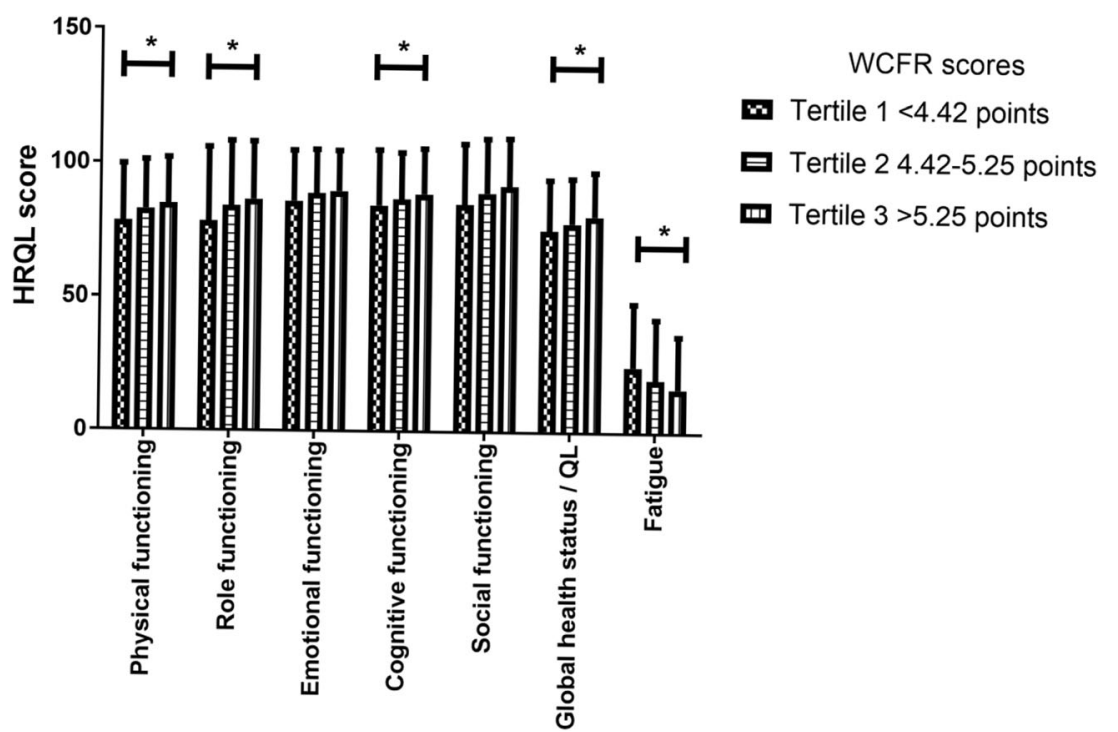


Table 2 The association between overall WCRF/AICR adherence score and HRQL and fatigue using multivariable linear regression $(N=1096)$

\begin{tabular}{lllll}
\hline HRQL & \multicolumn{2}{l}{ WCRF adherence scores } & & Continuous \\
\cline { 2 - 5 } & \multicolumn{2}{l}{ Tertile 1} & Tertile 2 \\
& $<.42-5.25$ points & Tertile 3 & $>5.25$ points & \\
\hline Physical functioning & REF & $3.88(4.42,6.33)^{*}$ & $6.94(4.46,9.42)^{*}$ & $2.71(1.73,3.68)^{*}$ \\
Role functioning & REF & $4.76(1.40,8.12)^{*}$ & $7.49(4.09,10.89)^{*}$ & $2.87(1.53,4.21)^{*}$ \\
Emotional functioning & REF & $2.35(-0.06,4.75)$ & $3.34(0.90,5.77)^{*}$ & $0.85(-0.11,1.81)$ \\
Cognitive functioning & REF & $1.90(-0.77,4.57)$ & $3.48(0.78,6.17)^{*}$ & $1.25(0.19,2.32)^{*}$ \\
Social functioning & REF & $3.56(0.67,6.44)^{*}$ & $6.12(3.21,9.04)^{*}$ & $2.01(0.85,3.16)^{*}$ \\
Global health status/QL & REF & $1.68(-0.70,4.07)$ & $4.33(1.92,6.74)^{*}$ & $1.64(0.69,2.59)^{*}$ \\
fatigue & REF & $-3.87(-6.90,-0.84)^{*}$ & $-7.65(-10.72,-4.59)^{*}$ & $-2.81(-4.02,-1.60)^{*}$ \\
\hline
\end{tabular}

Results are expressed as $\beta$ (95\% confidence interval (CI)). All models were adjusted for age, gender, comorbidities and smoking. An increase in functioning scores and global health status indicates an improvement in HRQL. A decrease in fatigue scores indicates an improvement in fatigue

$* p<0.05$

HRQL and fatigue scores compared to participants with a healthy weight. However, being obese was significantly associated with lower physical functioning compared to healthy weight respondents. Adherence to the dietary recommendations was not associated with the different functioning scales, global health status or fatigue.

\section{Discussion}

Higher adherence to the WCRF/AICR recommendations was associated with better physical functioning, role functioning, social functioning and global health status and less fatigue among CRC survivors. Physical activity seemed to be the main component of the WCRF/AICR recommendations contributing to the observed associations. Being obese was associated with worse physical functioning. Diet was not associated with the different functioning scales, global health status and fatigue.

Previous studies showed an association between higher adherence to the non-cancer-specific Healthy Eating Index or the Mediterranean diet and higher levels of HRQL in cancer survivors, including CRC survivors [5-7]. Our study did not show an association between the specific dietary recommendations of the WCRF/AICR and HRQL, however when looking at the total adherence WCRF/AICR recommendations score, an association between level of adherence and HRQL was found in CRC survivors similar to the association with the Healthy Eating Index or the Mediterranean diet [5-7]. Our study only found an inverse association between being obese and physical functioning. Our findings are in line with the results of InoueChoi who showed that higher adherence to the WCRF/AICR recommendations, especially to the physical activity recommendations, was significantly associated with higher physical and mental component summary scores (SF-36) in a population of female cancer survivors with different cancer types [10]. Our results are also in line with the results of Breedveld-Peters et al. who found that higher adherence to the total set of WCRF/AICR recommendations was associated with better physical functioning and less fatigue in a small group $(N=$ 145) of CRC survivors in the Netherlands [12].

Of all recommendations, physical activity was most strongly associated with most functioning scales: physical, role, emotional and social functioning; global health status and fatigue in our study. When investigating the crude model, diet was associated with physical functioning. However, when we adjusted for physical activity, as discussed in the "Subjects and Methods" section, the association was no longer significant. This indicates that physical activity indeed was the main component of the WCRF/AICR associated with a better HRQL and not diet.

For fatigue, there is ample evidence that physical activity has a positive influence [25]. This is also in line with the US National Comprehensive Cancer Network guidelines for managing fatigue [26]. Two observational studies recommended that CRC survivors should meet the public health exercise guideline ( $>150 \mathrm{~min}$ of moderate to strenuous intensity exercise or $>60 \mathrm{~min}$ of strenuous intensity exercise per week), since CRC survivors who meet these standards had a higher quality of life than other survivors who did not meet these exercise guidelines $[8,14]$. However, to be able to be physically active, a healthy diet and body weight are important. This is supported by our finding that being obese was negatively associated with physical functioning. Therefore, it remains important to focus on the triad of physical activity, diet and body weight when targeting CRC survivors, as was also suggested by Blanchard et al. [27].

The differences found in functioning scales when comparing respondents with the highest WCRF/AICR adherence scores $(>5.25)$ to those with the lowest scores $(<4.42)$ are subtle but nevertheless clinically meaningful, meaning that these differences are noticeable in daily clinical practice [19].

The present study was the first study investigating the associations between adherence to the cancer-specific 
WCRF/AICR recommendations and HRQL, in a large group of male and female CRC survivors. Major strengths of our study are the large sample size that made it possible to investigate the association between diet, physical activity and body fatness on HRQL separately, and the registry-based character of the study. However, there are also some limitations. First, selection bias may limit the generalizability of our findings. The present study covers CRC stage I-IV, with a mean time since diagnosis of 8.1 years. Patients with a worse prognosis or worse health might be less likely to participate in the study, might have more problems to complete the follow-up questionnaires or might have already died. Although our included participants were older and more often former smokers than the excluded participants, our study population may consist of more healthy CRC survivors possibly with different associations between a healthy lifestyle and HRQL. Absolute HRQL scores of our CRC survivors should be interpreted cautiously and are not generalizable for the whole population of CRC survivors. Second, data in our study were self-reported by survivors, which might have led to underreporting (body weight) and overreporting (physical activity, consumption of vegetable and fruits) due to social desirable answers [28-31]. Self-reporting of nutritional intake may lead to differential misclassification: obese participants might underreport their intake more than non-obese participants and elderly might be more eager to present themselves in a favourable way, giving a social desirable answer, hence their higher WCRF/AICR scores 32. Also non-differential misclassification might have occurred, probably leading to higher WCRF/AICR adherence scores. However, only one respondent had a total score of 8 points and the percentage survivors adhering to specific recommendations e.g., more plant-based foods, less red meat was often low, demonstrating how hard it is for CRC survivors and for the general public to adhere to the WCRF/AICR recommendations. Third, $75 \%$ of respondents reported to meet the guidelines for physical activity. This might be an overestimation, due to the nature of measuring physical activity: by means of a questionnaire (SQUASH) and not by the use of activity trackers. Fourth, the scoring of fatigue and other functioning scales by use of the EORTC QLQ-C30 may not be the best way to determine HRQL, especially fatigue, so many years after treatment. However, the EORTC QLQ-C30 is the most common questionnaire to determine HRQL in cancer survivors. Hence, it makes it easy to compare our results to the work of others.

Finally, due to the study design, with 6 months between the questionnaire on adherence to the WCRF recommendations and the questionnaire on HRQL in a cohort with a mean time since diagnosis of 8.1 years, we cannot draw conclusions whether the association between HRQL and adherence to the WCRF/AICR recommendations reflects a causal relation or reverse causation which means that survivors who have a better HRQL easier adhere to the WCRF/AICR recommendations. 


\section{Conclusion}

Higher adherence to the WCRF/AICR recommendations was associated with better physical, role, cognitive and social functioning, better global health status and less fatigue among CRC survivors. Physical activity seemed to be the main contributor to higher scores on most functioning scales and global health status and lower scores on fatigue in CRC survivors.

Because CRC survivors with the highest adherence to the WCRF/AICR recommendations also report the highest HRQL, we recommend to investigate whether increasing the adherence in CRC survivors indeed results in better HRQL. However, previous research as well as the present study has shown that it is very difficult to motivate cancer survivors to positively change their lifestyle $[12,20]$. Even Lynch syndrome carriers, with a very high inherited risk of developing CRC [33], from whom we hoped that they would be extremely motivated to change their lifestyle, were shown to adhere to those recommendations only in a slightly better manner than CRC survivors without Lynch syndrome. Adhering to the WCRF/AICR recommendations can be challenging for CRC survivors. Thus, trials aiming to increase adherence should not only focus on the effects better adherence has on cancer outcomes but also on tools to stimulate and motivate CRC survivors to follow the recommendations to the best of their abilities.

Acknowledgements The authors thank the registration teams of the Netherlands Comprehensive Cancer Organisation for the collection of data for the Netherlands Cancer Registry and members of the PROFILES registry for distribution and handling of the questionnaires. We are very grateful for the participation of all patients and their doctors in the study. Special thanks go to Dr. M. van Bommel, who was willing to function as an independent advisor and to answer questions of patients. We also want to thank the following hospitals for their cooperation: Amphia hospital, Breda; Bernhoven Hospital, Uden; Catharina hospital, Eindhoven; Elisabeth-TweeSteden hospital, Tilburg and Waalwijk; Elkerliek Hospital, Helmond; Jeroen Bosch hospital, 's Hertogenbosch; Maxima Medical Centre, Eindhoven and Veldhoven; Sint Anna hospital, Geldrop; VieCury hospital, Venlo and Venray.

Funding The present study was supported by a grant from the Alpe d'HuZes Foundation within the research programme 'Leven met kanker' of the Dutch Cancer Society (grant no. UM-2012-5653). In addition, the present study was supported by a VENI grant (\#451-10-041) from the Netherlands Organization for Scientific Research awarded to FM. MV is supported by a grant from Alpe d'HuZes/Dutch Cancer Society, in the project 'A taskforce on nutrition and cancer' (IKZ 2012-5426) and MJB is supported by a grant from Kankeronderzoekfonds Limburg as part of Health Foundation Limburg (grant no. 00005739).

\section{Compliance with ethical standards}

Conflict of interest The authors declare that they have no conflict of interest.

Research involving human participants Ethical approval for the study was obtained from the local certified Medical Ethics Committee of the Maxima Medical Centre Veldhoven, the Netherlands (approval number 0822).
Informed consent Informed consent was obtained from all individual participants included in the study.

Data We have control over all primary data, we agree to allow the journal to review our data if requested.

Open Access This article is distributed under the terms of the Creative Commons Attribution 4.0 International License (http:// creativecommons.org/licenses/by/4.0/), which permits unrestricted use, distribution, and reproduction in any medium, provided you give appropriate credit to the original author(s) and the source, provide a link to the Creative Commons license, and indicate if changes were made.

\section{References}

1. World Cancer Research Fund and American Institute for Cancer Research (2007) Food, nutrition, physical activity, and the prevention of cancer: a global perspective. AICR, Washington DC

2. Miller KD, Siegel RL, Lin CC, Mariotto AB, Kramer JL, Rowland JH, Stein KD, Alteri R, Jemal A (2016) Cancer treatment and survivorship statistics, 2016. CA Cancer J Clin 66(4):271-289

3. Marventano S, Forjaz M, Grosso G, Mistretta A, Giorgianni G, Platania A, Gangi S, Basile F, Biondi A (2013) Health related quality of life in colorectal cancer patients: state of the art. BMC Surg 13(2):S15

4. Jansen L, Koch L, Brenner H, Arndt V (2010) Quality of life among long-term ( $\geqslant 5$ years) colorectal cancer survivors-systematic review. Eur J Cancer 46(16):2879-2888

5. Schlesinger S, Walter J, Hampe J, von Schönfels W, Hinz S, Küchler T, Jacobs G, Schafmayer C, Nöthlings U (2014) Lifestyle factors and health-related quality of life in colorectal cancer survivors. Cancer Causes Control 25(1):99-110

6. Sánchez PH et al (2012) Adherence to the Mediterranean diet and quality of life in the SUN Project. Eur J Clin Nutr 66(3):360-368

7. Mosher CE, Sloane R, Morey MC, Snyder DC, Cohen HJ, Miller PE, Demark-Wahnefried W (2009) Associations between lifestyle factors and quality of life among older long-term breast, prostate, and colorectal cancer survivors. Cancer 115(17):4001-4009

8. Peddle CJ, Au H-J, Courneya KS (2008) Associations between exercise, quality of life, and fatigue in colorectal cancer survivors. Dis Colon Rectum 51(8):1242-1248

9. Courneya $\mathrm{K}$ et al (2003) A randomized trial of exercise and quality of life in colorectal cancer survivors. Eur J Cancer Care 12(4):347357

10. Inoue-Choi M, Lazovich D, Prizment AE, Robien K (2013) Adherence to the World Cancer Research Fund/American Institute for Cancer Research recommendations for cancer prevention is associated with better health-related quality of life among elderly female cancer survivors. J Clin Oncol 31(14):1758-1766

11. Lei Y-Y, Ho SC, Cheng A, Kwok C, Lee CKI, Cheung KL, Lee R, Loong HHF, He YQ, Yeo W (2018) Adherence to the World Cancer Research Fund/American Institute for Cancer Research Guideline is associated with better health-related quality of life among Chinese patients with breast cancer. J Natl Compr Cancer Netw 16(3):275285

12. Breedveld-Peters, J.J., et al., Colorectal cancers survivors' adherence to lifestyle recommendations and cross-sectional associations with health-related quality of life. Br J Nutr, 2018: p. 1-10

13. van de Poll-Franse LV et al (2011) The Patient Reported Outcomes Following Initial treatment and Long term Evaluation of Survivorship registry: scope, rationale and design of an 
infrastructure for the study of physical and psychosocial outcomes in cancer survivorship cohorts. Eur J Cancer 47(14):2188-2194

14. Husson O, Mols F, Ezendam NPM, Schep G, van de Poll-Franse LV (2015) Health-related quality of life is associated with physical activity levels among colorectal cancer survivors: a longitudinal, 3-year study of the PROFILES registry. J Cancer Surviv 9(3):472-480

15. Aaronson NK, Ahmedzai S, Bergman B, Bullinger M, Cull A, Duez NJ, Filiberti A, Flechtner H, Fleishman SB, Haes JCJM, Kaasa S, Klee M, Osoba D, Razavi D, Rofe PB, Schraub S, Sneeuw K, Sullivan M, Takeda F (1993) The European Organization for Research and Treatment of Cancer QLQ-C30: a quality-of-life instrument for use in international clinical trials in oncology. J Natl Cancer Inst 85(5):365-376

16. Whistance R, Conroy T, Chie W, Costantini A, Sezer O, Koller M, Johnson CD, Pilkington SA, Arraras J, Ben-Josef E, Pullyblank AM, Fayers P, Blazeby JM, European Organisation for the Research and Treatment of Cancer Quality of Life Group (2009) Clinical and psychometric validation of the EORTC QLQ-CR29 questionnaire module to assess health-related quality of life in patients with colorectal cancer. Eur J Cancer 45(17):3017-3026

17. Vissers PA et al (2016) Prospectively measured lifestyle factors and BMI explain differences in health-related quality of life between colorectal cancer patients with and without comorbid diabetes. Support Care Cancer 24(6):2591-2601

18. Fayers, P.M., et al., EORTC QLQ-C30 scoring manual. 2001

19. Cocks K, King MT, Velikova G, Martyn St-James M, Fayers PM, Brown JM (2011) Evidence-based guidelines for determination of sample size and interpretation of the European Organisation for the Research and Treatment of Cancer Quality of Life Questionnaire Core 30. J Clin Oncol 29(1):89-96

20. Winkels RM, van Lee L, Beijer S, Bours MJ, van Duijnhoven FJB, Geelen A, Hoedjes M, Mols F, de Vries J, Weijenberg MP, Kampman E (2016) Adherence to the World Cancer Research Fund/American Institute for Cancer Research lifestyle recommendations in colorectal cancer survivors: results of the PROFILES registry. Cancer Med 5(9):2587-2595

21. Romaguera D, Vergnaud AC, Peeters PH, van Gils CH, Chan DSM, Ferrari P, Romieu I, Jenab M, Slimani N, Clavel-Chapelon F, Fagherazzi G, Perquier F, Kaaks R, Teucher B, Boeing H, von Rüsten A, Tjønneland A, Olsen A, Dahm CC, Overvad K, Quirós JR, Gonzalez CA, Sánchez MJ, Navarro C, Barricarte A, Dorronsoro M, Khaw KT, Wareham NJ, Crowe FL, Key TJ, Trichopoulou A, Lagiou P, Bamia C, Masala G, Vineis P, Tumino R, Sieri S, Panico S, May AM, Bueno-de-Mesquita HB, Büchner FL, Wirfält E, Manjer J, Johansson I, Hallmans G, Skeie G, Benjaminsen Borch K, Parr CL, Riboli E, Norat T (2012) Is concordance with World Cancer Research Fund/American Institute for Cancer Research guidelines for cancer prevention related to subsequent risk of cancer? Results from the EPIC study. Am J Clin Nutr 96(1):150-163
22. van Lee L et al (2012) The Dutch Healthy Diet index (DHD-index): an instrument to measure adherence to the Dutch Guidelines for a Healthy Diet. Nutr J 11(1):49

23. Wendel-Vos GW et al (2003) Reproducibility and relative validity of the short questionnaire to assess health-enhancing physical activity. J Clin Epidemiol 56(12):1163-1169

24. Sullivan LM (2011) Essentials of biostatistics in public health. Jones \& Bartlett Publishers, Burlington, p 212

25. Cormie P, Zopf EM, Zhang X, Schmitz KH (2017) The impact of exercise on cancer mortality, recurrence, and treatment-related adverse effects. Epidemiol Rev 39(1):71-92

26. Berger AM, Mooney K, Alvarez-Perez A, Breitbart WS, Carpenter KM, Cella D, Cleeland C, Dotan E, Eisenberger MA, Escalante CP, Jacobsen PB, Jankowski C, LeBlanc T, Ligibel JA, Loggers ET, Mandrell B, Murphy BA, Palesh O, Pirl WF, Plaxe SC, Riba MB, Rugo HS, Salvador C, Wagner LI, Wagner-Johnston ND, Zachariah FJ, Bergman MA, Smith C, National comprehensive cancer network (2015) Cancer-related fatigue, version 2.2015. J Natl Compr Cancer Netw 13(8):1012-1039

27. Blanchard CM, Stein KD, Baker F, Dent MF, Denniston MM, Courneya KS, Nehl E (2004) Association between current lifestyle behaviors and health-related quality of life in breast, colorectal, and prostate cancer survivors. Psychol Health 19(1):1-13

28. Krebs-Smith SM, Heimendinger J, Subar AF, Patterson BH, Pivonka E (1995) Using food frequency questionnaires to estimate fruit and vegetable intake: association between the number of questions and total intakes. J Nutr Educ 27(2):80-85

29. Feskanich D, Ziegler RG, Michaud DS, Giovannucci EL, Speizer FE, Willett WC, Colditz GA (2000) Prospective study of fruit and vegetable consumption and risk of lung cancer among men and women. J Natl Cancer Inst 92(22):1812-1823

30. Skender S, Ose J, Chang-Claude J, Paskow M, Brühmann B, Siegel EM, Steindorf K, Ulrich CM (2016) Accelerometry and physical activity questionnaires-a systematic review. BMC Public Health 16(1):515

31. Pusatcioglu C, Braunschweig C (2011) Moving beyond diet and colorectal cancer. J Am Diet Assoc 111(10):1476-1478

32. Dijkstra W, Smit JH, Comijs HC (2001) Using social desirability scales in research among the elderly. Qual Quant 35(1):107-115

33. Howlader $\mathrm{N}$ et al (2011. Also available online Last ac, 2011) SEER Cancer Statistics Review, 1975-2008. National Cancer Institute, Bethesda, pp 140-143

Publisher's note Springer Nature remains neutral with regard to jurisdictional claims in published maps and institutional affiliations. 